\title{
Asteroids and andesites
}

\author{
Arising from: J. M. D. Day et al. Nature 457, 179-182 (2009)
}

The production of terrestrial andesites in subduction zones is well established. Day et al. ${ }^{1}$ describe two examples of meteorites (GRA 06128 and GRA 06129) that they claim to represent "an entirely new mode of generation of andesite crust compositions" on asteroids; this suggestion has wide implications for the generation of andesitic planetary crusts in general. However, here we show that compositional data, particularly for the rare-earth elements (REEs) and other lithophile elements, presented in their paper ${ }^{1}$ do not substantiate this claim. We conclude that existing mechanisms for andesite generation do not need revision.

Day et al. ${ }^{1}$ present two relevant figures. The first (Fig. 1a in ref. 1) is a plot of $\mathrm{Na}_{2} \mathrm{O}$ plus $\mathrm{K}_{2} \mathrm{O}$ versus $\mathrm{SiO}_{2}$ that falls marginally within the andesite field. We consider that this figure could be misleading, as it is dominated by an exceptionally high $\mathrm{Na}_{2} \mathrm{O}$ content $(6 \%)$ and should not have been used to infer that their samples have andesitic affinities.

The second figure (Fig. $1 \mathrm{~b}$ in ref. 1) is a chondrite-normalized REE plot; we note that Day et al. also present data for the age, platinum group elements, Re-Os systematics and oxygen isotopes of the samples that do not directly address their thesis. REE values are very low (La varies between 0.95 and 1.48 p.p.m. or 2.6 to 4 times chondritic using volatile-free CI values for normalization). The chondrite-normalized REE patterns in these meteorites are flat but with a significant enrichment in $\mathrm{Eu}$. These patterns are comparable, if a little lower than those of 'Eu-rich', albeit otherwise 'normal' eucrites ${ }^{2}$ (basaltic meteorites derived from the asteroid 4 Vesta) and do not at all resemble that of the 'average terrestrial andesite' REE pattern (or the majority of terrestrial arc andesites) that is also shown in the same figure. This pattern has a strong enrichment in the light REEs (for example, La $=16$ p.p.m. (ref. 3 ) compared to 0.95-1.48 p.p.m. La for the meteorites). We believe that differences by factors of more than 10 need to be considered.

From the data given in the Supplementary Information of ref. 1, the sodium content (around 6\%) is a factor of two higher, and the potassium content (about $0.2 \%$ ) a factor of six lower, than averages for andesites or for the continental crust of the Earth. Indeed, the elevated silica in these rocks results from the high albite composition of the plagioclase, which dominates the mineralogy. In addition to the REEs, other significant lithophile elements such as $\mathrm{Li}, \mathrm{Rb}, \mathrm{Sr}, \mathrm{Cs}$, $\mathrm{Zr}, \mathrm{Hf}, \mathrm{Nb}, \mathrm{Ba}, \mathrm{Pb}, \mathrm{U}$ and Th also show major discrepancies compared to their values in the continental crust, with the most incompatible of these (Th, Cs) being depleted by factors of 40 or more.

So although these meteorites are very interesting examples with high silica values (around 55\%) that arose early $(4.52 \mathrm{Gyr}$ ) on an asteroid, their compositions are fundamentally different from terrestrial andesites, and this study does not demonstrate that andesitic crusts resembling anything like the continental crust of the Earth might have evolved on such asteroids. Labelling these samples as 'andesite' carries the implication that the origin of these rocks has lessons for the formation of the continental crust of the Earth or elsewhere, and could be misleading.

Richard Arculus', Ian H. Campbell', Scott M. McLennan ${ }^{2} \&$

Stuart Ross Taylor ${ }^{1}$

${ }^{1}$ Research School of Earth Sciences, Australian National University, Canberra, Australian Capital Territory 0200, Australia.

e-mail: Ross.Taylor@anu.edu.au

${ }^{2}$ Department of Geosciences, State University of New York at Stony Brook, Stony Brook, New York 11794-2100, USA.

Received 2 February; accepted 24 April 2009.

1. Day, J. M. D. et al. Early formation of evolved asteroidal crust. Nature 457, 179-182 (2009).

2. Mittlefehldt, D. W. \& Lindstrom, M. M. Geochemistry of diverse lithologies in Antarctic eucrites. Lunar Planet. Sci. XIX, abstr. 790-1 (1988)

3. Taylor, S. R. \& McLennan, S. M. Planetary Crusts: Their Composition, Origin and Evolution Table 11.4 (Cambridge Univ. Press, 2009).

doi:10.1038/nature08077

\section{Day et al. reply}

Replying to: R. Arculus, I. H. Campbell, S. M. McLennan \& S. R. Taylor Nature 459, doi:10.1038/nature08077 (2009)

Arculus et al. ${ }^{1}$ raise an important question regarding the use of terrestrial rock nomenclature to characterize extraterrestrial materials. Here the issue relates to the definition of 'andesite', and whether the felsic achondrite meteorites GRA 06128 and GRA 06129 (GRA $06128 / 9$ ) can and should be classified using this term ${ }^{2}$. More broadly, the question is whether extraterrestrial rocks should be classified using standard petrologic and geochemical criteria, such as mineralogy and major-element bulk composition, developed for the description of terrestrial rocks ${ }^{3,4}$. The approach of Arculus et al. ${ }^{1}$ is that petrogenetic process is of equal or greater importance when classifying a rock. This question must ultimately be decided by the scientific community.

Examples of the difficulties associated with extraterrestrial rock nomenclature are numerous in planetary petrology. Materials derived from the lunar maria are termed 'basalt' despite enormous diversity in their trace-element compositions, and have a different mode-of-origin as compared to terrestrial basalts ${ }^{5}$. Furthermore, meteoritic 'basalts' from Mars and from the asteroid belt (basalt is a term used by Arculus et al. ${ }^{1}$ to describe the eucrites) carry with them no inference that they formed under the same petrogenetic conditions as terrestrial basalts. Similarly, 3.9 to 4.4-Gyr-old lunar felsites displaying dry mineral assemblages have been commonly termed 'granites', despite some opinion that granite can only form in water-rich environments ${ }^{7}$. The Moon is also populated by norite, gabbro, anorthosite, troctolite, granulite and so forth ${ }^{5}$, all of which are nomenclature terms used to describe terrestrial rocks and whose lunar genesis differs from their terrestrial counterparts.

Terrestrial andesite is commonly defined using two classification schemes from the International Union of Geological Sciences ${ }^{3,4}$. First, with a petrological classification, as a rock chiefly composed of plagioclase feldspar with subordinate accessory minerals, such as pyroxene, olivine or hornblende. Second, using the chemical classification as shown in Fig. 1 of our paper ${ }^{2}$. GRA 06128/9 qualify as andesite using either of these classifications. The rare-earth elements (REEs) and other lithophile trace elements have not commonly been used to define terrestrial or extra-terrestrial rocks, as suggested by Arculus et al. ${ }^{1}$; however, we acknowledge that these elements are important petrogenetic indicators. 
We suggest that some asteroids may have crustal material that shares compositional and mineralogical similarities with the Earth's average continental crust, but we do not suggest a similar mechanism for its generation ${ }^{2}$. The generation of GRA 06128/9 is probably not plate tectonics, but through low degrees of partial melting of a relatively undifferentiated asteroidal body, as we demonstrated, and for which the Re-Os and oxygen isotope, age and platinum-group element data provide important evidence. This process may have been an important mechanism for evolved crust formation in the early Solar System ${ }^{2}$. Indeed, if rocks with andesitic compositions are discovered on planetary bodies other than Earth (for example, Mars or asteroids), they might have origins that differ from terrestrial andesites, which are commonly products of watercharged subduction processes.

Given the prior applications of terrestrial rock nomenclature to extraterrestrial rocks, as well as the common petrologic and geochemical definitions of the term andesite, we believe it is an appropriate term to use to describe the achondrites GRA 06128/9.

J. M. D. Day ${ }^{1}$, R. D. Ash' ${ }^{1}$, Y. Liu ${ }^{2}$, J. J. Bellucci' ${ }^{1}$ D. Rumble III ${ }^{3}$, W. F. McDonough', R. J. Walker \& L. A. Taylor ${ }^{1}$
1Department of Geology, University of Maryland, College Park, Maryland 20742, USA.

e-mail: jamesday@geol.umd.edu

${ }^{2}$ Department of Earth and Planetary Sciences, Planetary Geosciences Institute, University of Tennessee, Knoxville, Tennessee 37996, USA.

${ }^{3}$ Geophysical Laboratory, Carnegie Institution of Washington, Washington DC 20015, USA.

1. Arculus, R., Campbell, I. H., McLennan, S. M. \& Taylor, S. R. Asteroids and andesites. Nature 459, doi:10.1038/nature08077 (2009).

2. Day, J. M. D. et al. Early formation of evolved asteroidal crust. Nature 457, 179-182 (2009).

3. Le Maitre, R. W. (ed.) A Classification of Igneous Rocks and Glossary of Terms: Recommendations of the International Union of Geological Sciences Subcommission on the Systematics of Igneous Rocks (Blackwell Scientific, 1989).

4. Le Bas, M. J. \& Streckeisen, A. L. The IUGS systematics of igneous rocks. J. Geol. Soc. Lond. 148, 825-833 (1991)

5. Jolliff, B. L., Wiezorek, M. A., Shearer, C. K. \& Neal, C. R. (eds) New Views of the Moon (Reviews in Mineralogy and Geochemistry, Vol. 60, Mineralogical Society of America, 2006).

6. Bonin, B., Bébien, J. \& Masson, P. Granite: a planetary point of view. Gondwana Res. 5, 261-273 (2002).

7. Campbell, I. H. \& Taylor, S. R. No water, no granites - no oceans, no continents. Geophys. Res. Lett. 10, 1061-1064 (1983).

doi:10.1038/nature08078 